procedure. It may be tempting to conclude that subsequent passage of a calculus after ureteric catheterization is a consequence of the manœuvre, but such a conclusion is unjustified.

There may be a place for giving osmotic diuretics, such as intravenous infusions of urea. The "stone basket" for extracting the calculus has limitations: its use is restricted to calculi in the distal third of the ureter, and in the patient with impacted stone-the very case that may require the most careful and precise treatment-it is frequently impossible to get the basket beyond the stone, and injudicious manipulation may be followed by damage to the ureter and subsequent stenosis of it. Whatever method is employed for the management of ureteric calculi, patients should remain under regular surveillance, for recurrent calculi are apt to develop in about $20 \%$ of cases.

\section{Irradiation of Food}

In answer to a parliamentary question on 4 July Mr. Kenneth Robinson, Minister of Health, announced that he and other Ministers concerned had accepted the Report of the Working Party on Irradiation of Food. ${ }^{12}$ Regulations will now be introduced under the Food and Drugs Act to prohibit the irradiation of food and food products intended for human consumption, and the sale in this country of food which has been irradiated. But this legislation will in fact result in the setting up of machinery for obtaining official approval for specific processes. A scrutinizing body will be established to advise on applications for exemptions from the prohibition. The equivalent of a " permitted list" might appear, as is the case with certain classes of food additives.

Similar prohibitive legislation was made in the Federal Republic of Germany in 1959 and is under consideration in other countries. Another approach to legislation is to invoke existing regulations such as those governing food additives, with or without explicit mention of irradiated foods or definition of food irradiation as a food additive. In Canada two irradiated foods have already been approved for human consumption, potatoes and onions, and the requests for approval were dealt with under the food additive regulations. The first commercially operated food irradiation plant, situated near Montreal, began operation in 1965, and is used for the treatment of potatoes to inhibit sprouting. Food irradiation is also dealt with as a food additive in the U.S.A., where wheat, potatoes, and bacon have already been cleared by the Food and Drug Administration, although no fully commercial processes are yet operating. However, a pilot plant for the disinfestation of grain by irradiation has been completed there, and another is planned in Turkey.

International organizations are studying legislative procedures in different countries so as to give guidance on international trade in irradiated products, and a joint report on the technical basis for legislation has just been published. ${ }^{3}$ In the meantime research into various aspects of food irradiation will continue in Great Britain, ${ }^{4}$ with particular interest in processes aimed at extending the refrigeration life of meat and fish and

\footnotetext{
1 Report of the Working Party on Irradiation of Food, 1964. Ministry of Health, H.M.S.O.

2 Brit. med. F., 1964, 2, 1088.

3 The Technical Basis for Legislation on Irradiated Food. Report of joint F.A.O./I.A.E.A./W.H.O. Expert Committee, 1966. H.M.S.O.

- Brit. med. F., 1964, 1, 1330.
}

at the elimination of salmonellae from certain imported foods. ${ }^{4}$

\section{Boric Acid and Babies}

Boric (or boracic) acid and borax (sodium borate) may cause serious harm to infants, and many deaths have resulted from their use. Now a statement from the British Medical Association is published this week (p. 233) advising doctors not to prescribe them for infants.

The symptoms of intoxication are diarrhoea and vomiting, cramp, haematemesis, melaena, a red beefy rash covering the entire body, and peripheral circulatory failure. Necropsy shows cloudy swelling of the kidney, central necrosis of the liver, and haemorrhagic enteritis. ${ }^{1}$ It is easy to see how the diagnosis of gastro-enteritis could be made because of the diarrhoea and vomiting when in fact the symptoms are due to boric acid poisoning. When in doubt a simple test should give the answer. The urine is acidified by dilute hydrochloric acid, and turmeric paper is inserted ; the paper becomes red, changing to dark green on adding ammonia or dilute sodium hydroxide.

R. B. Goldbloom and A. Goldbloom ${ }^{2}$ described four cases of boracic acid poisoning and reviewed 109 others. The overall mortality was $55 \%$, but in infants under 1 year old it was $70 \%$. They emphasized that there may be considerable absorption from broken surfaces and mucous membranes. L. C. Wong and colleagues ${ }^{3}$ reported more recently on 11 infants who accidentally received boric acid in the diet. Five of them died. These authors, as others have done, question whether boric acid is of sufficient therapeutic value to justify these occasional grave mishaps. The 1966 edition of the British National Formulary includes borax glycerin, B.P.C., in the "Dental Practitioners Formulary," and boric acid ear drops, B.P.C. for " the later toilet of the ear."

Borax glycerin is a highly dangerous preparation to put in a baby's mouth because of the absorption from the mucous membrane. Mothers soak the dummy in this mixture for so-called teething, and its use for this purpose should be stopped. In any case the use of glycerin or similar material on a dummy is thoroughly undesirable for older babies, because of its disastrous effect on their teeth. There is in fact no place for any local application to palliate the troubles of teething. It seems unlikely that boric acid ear drops for the toilet of the ear will present danger, but their value is at least questionable. There is the ever-present danger that someone will attempt to treat acute otitis media with ear drops instead of giving an antibiotic, such as penicillin, by injection or by mouth.

Boric acid crystals should never be sprinkled on to the napkin for the treatment of a napkin rash because of the serious risk of absorption. Nor, for the same reason, should napkins be washed out in boric acid solution. Boric acid should not be applied in any form to a napkin rash except only as a constituent of dusting powder : $5 \%$ boric acid in talc is not absorbed through the intact skin. ${ }^{4-6}$ This substance is added to the powder to neutralize the alkalinity due to the

\footnotetext{
1 Brooke, C., and Boggs, T., Amer. F. Dis. Child., 1951, 82, 465.

2 Goldbloom, R. B., and Goldbloom, A., Ұ. Pediat., 1953, 43, 631. Wong, L. C., Heimbach, M. D., Truscott, D. R., and Duncan, B. D.,
Canad. med. Ass. F., 1964, 90, 1018 .

4 Fisher, R. S., Lancet, 1954, 2, 494

5 Vignec, A. J., and Ellis, R., Amer. F. Dis. Child., 1954, 88, 72

6 Johnstone, D. E., Basila, N., and Glaser, J., F. Pediat., 1955, 46, 160 Fergusson. A. G., Fraser, N. G., and Grant, P. W., Brit. F. Derm. $1966,78,289$.

s Warin, R. P., and Faulkner, K. E., ibid., 1961, 73, 445.
} 
2 to $6 \%$ calcium oxide in commercial talcs. When the talc is wetted the boric acid reacts with the calcium hydroxide to produce the highly insoluble calcium borate. Absorption from dusting powder when the surface of the skin is intact is negligible and harmless, but if the surface is broken a dusting powder is probably not the best treatment anyway.

It should be recognized that there is no single blunderbuss method of treating napkin rashes, because they are not all of the same type or due to the same cause. The common ammonia dermatitis, with its diffuse erythema where the wet napkin was in contact with the skin, leaving the creases clear, is due to the liberation of ammonia from the urine by urea-splitting organisms from the stools. This is encouraged by leaving the napkins on in a wet state for prolonged periods. A variety of preparations offer effectual treatment, including quaternary ammonium compounds. A useful lotion is one containing $4 \%$ tannic acid in $0.1 \%$ proflavine. It is essential to see that the napkins are changed sufficiently frequentlyand that the mother has enough of them to make this possible.

Isolated vesicles in the napkin urea are likely to be due to monilia. They may be numerous, and may coalesce. Nystatin ointment usually clears the rash satisfactorily. The so-called psoriasiform napkin dermatitis has been the subject of recent studies. ${ }^{78}$ A. G. Fergusson and colleagues ${ }^{7}$ write that it begins as a napkin dermatitis and later spreads to affect the trunk, limbs, and scalp. They describe 52 cases, and consider that it is a response to monilia in a child with a seborrhoeic type of skin. The growth of monilia may be the result of the administration of antibiotics by mouth. The condition does not respond to nystatin ointment but does to corticosteroid ointment, such as betamethasone five parts and Lassar's paste one part.

All these rashes have to be distinguished from seborrhoeic eczema ; in this the skin of the flexures of the napkin area is attacked, and there are characteristic clear areas round the red patches. It usually responds to triamcinolone-andchlorhydroxyquinoline ointment with equal parts of Lassar's paste.

\section{Facial Myokymia}

Twitching of the face is common and usually benign. The simple tic or habit spasm is a movement of the faciai musculature, often bilateral, which appears involuntary; but it is probably in the first instance consciously performed to relieve tension, and as the habit becomes established the patient is progressively less aware of the movements. Focal twitching of one corner of the mouth occurs episodically in focal Jacksonian epilepsy, and is usually easy to recognize. Recently it has become clear that certain persistent facial dyskinesias, in which there are pursing, chewing, and other bizarre movements of the lips and tongue, may result from long periods of treatment with phenothiazine drugs. The movements of chorea, whether of the Sydenham's or Huntington's type, frequently involve the facial musculature, and grimacing movements, which are slower but not otherwise dissimilar from those of chorea, are also seen in hepatolenticular degeneration (Wilson's disease).

More common, and often wrongly diagnosed, is clonic facial spasm (heini-facial spasm). This benign condition, which is always ascentuated by tension or embarrassment, affects only one 'ialf of the face ; it often begins with an intermittent and irregular twitching of the muscles around one eye, and later may spread to those around the mouth, so that intermittent sharp and momentary contractions of the entire facial musculature on one side may ensue. The probable cause is compression or irritation of the facial nerve within its bony canal, but regrettably there is no certain method of determining the site of the lesion, so that operations designed to decompress the affected nerve are rarely successful. A similar type of intermittent twitching may be seen following a severe Bell's palsy in association with the facial contracture which can occur as a result of partial regeneration in the facial nerve.

Yet another interesting and unusual form of involuntary movement of the facial musculature has been called "facial myokymia." F. Andermann and his colleagues ${ }^{1}$ described four personal cases and found seven in the literature ; of these 11 cases, eight were probably suffering from disseminated sclerosis. More recently, W. B. Matthews ${ }^{2}$ has described seven episodes of myokymia occurring in five patients whom he had observed personally over a six-year period. He points out that the onset of the condition is usually abrupt and that it seems to affect the whole musculature on one side. Patients often complain that the face feels screwed up or swollen, and some when looking in a mirror have observed flickering movements. The appearance is highly characteristic in that all of the muscles on the affected side of the face appear to be in a state of slight contraction; the palpebral fissure is narrowed, the angle of the mouth drawn up, and the lips are pursed. There is a continuous flickering from frontalis to platysma ; this differs from fasciculation, as it recurs with extraordinary rapidity and appears to pass over the face in rapid undulating waves. In Matthews's cases, the duration of the disorder varied; while showing some waxing and waning in intensity, it usually lasted for anything between three weeks and six months. One patient found all sounds seemed louder in the affected ear, but none had abnormalities of taste sensation. Electromyography showed rhythmical spontaneous discharges occurring in the affected muscles.

As Matthews points out, this syndrome of facial myokymia differs from the form of benign fasciculation in the limbs to which the name "myokymia" has also been given." This benign fasciculation is often widespread and "coarse" and is commonly accompanied by anxiety, muscle cramps, and excessive sweating. Electromyography in such cases usually shows grouped discharges of two or three motor units repeating at intervals, and thus differs from the spontaneous fasciculation activity observed in motor neurone disease, in which the potentials are usually single. Facial myokymia must also be distinguished from the benign myokymia of the lower eyelid which is often seen in normal people.

Facial myokymia has never been described after facial palsy; its onset is usually abrupt and eventual recovery appears to be invariable, though more than one attack may occur, and both sides of the face may be successively affected. Though there is no histopathological proof, it has been suggested that the lesion is probably intramedullary, lying close to the facial nucleus. H. Oppenheim ${ }^{4}$ first described the disorder in patients with multiple sclerosis, and E. H. Lambert and his colleagues ${ }^{5}$ reported it in a case of pontine

\footnotetext{
Andermann, F., Cosgrove, J. B. R., Lloyd-Smith, D. L., Gloor, P., and McNaughton, F. L., Brain, 1961, 84, 31

${ }^{2}$ Matthews, W. B., f. Neurol. Neurosurg. Psychiat., 1966, 29, 35

Denny-Brown, D., and Foley, J. M., Trans. Ass. Amer. Phycns, 1948

Oppenheim, H., Neurol. Zbl., 1917, 36, 142.

Lambert, E. H., Love, J G., and Mulder, D. W., Newsl. Amer. Ass. Electromyogr., Electrodiagn., 1961, 8, 8.
} 